Gut, 1986, 27, 849-857

\title{
Occurrence and distribution of a newly discovered peptide, galanin, in the mammalian enteric nervous system
}

\author{
A E BISHOP, J M POLAK, F E BAUER, N D CHRISTOFIDES, F CARLEI, \\ AND S R BLOOM \\ From the Departments of Histochemistry and Medicine, Royal Postgraduate Medical School, Hammersmith \\ Hospital, London
}

SUMmARY Galanin, a newly discovered peptide, was found throughout the gastrointestinal tract of man, pig, and rat, exclusively in nerves. The concentrations of immunoreactive galanin ranged from $3.7 \pm 0.7$ (mean $\pm S E M) ~ p m o l / g$ in rat antrum to $76.5 \pm 14.3 \mathrm{pmol} / \mathrm{g}$ in $\mathrm{pig}$ colon. The predominantly intrinsic origin of the galanin nerves was shown by the finding of the peptide in submucosal ganglion cells, the majority of which also contained VIP. Furthermore, neither extrinsic denervation of the gut nor administration of capsaicin, which selectively destroys extrinsic afferent fibres, had any significant effect on the galanin innervation. The caudal projection of galanin-immunoreactive fibres was demonstrated by complete transection of the gut, which led to their reduction in the 1 to $2 \mathrm{~cm}$ distal to the cut. The abundance of galanin in the innervation of the mammalian gut and its reported action on smooth muscle contractility suggest this peptide to be a novel regulatory factor in the control of bowel function.

The system of mammalian regulatory peptides continues to expand with the discovery of new active molecules. One of the latest peptides to be isolated and characterised has been termed galanin. ${ }^{1}$ The name of this 29 amino acid peptide was derived from the fact that its $\mathrm{N}$ - and C-terminal residues are glycine and alanine, respectively. Galanin has been reported to occur in rat brain and in the intestinal tract of mice, rats, guinea pigs, and pigs. ${ }^{2}{ }^{3}$ As yet, little is known about the actions of galanin but preliminary pharmacological experiments have shown that it causes smooth muscle contraction in rat gut and induces mild hyperglycaemia. ${ }^{14}$ In the present study, the techniques of immunocytochemistry and radioimmunoassay were used in combination to determine the distribution of galanin in the human, porcine and rodent gastrointestinal tracts and, using surgical and pharmacological manipulations, to examine the origin, projections and nature of galanin-containing nerves in the gut of the rat.

Address for correspondence: J M Polak, Department of Histochemistry, RPMS, Hammersmith Hospital, Du Cane Road, London W12 0HS.

Received for publication 25 October 1985

\section{Methods}

NORMAL TISSUES

Fresh specimens of human bowel (fundus, $n=8$; antrum, $n=11$; duodenum, $n=10$; jejunum, $n=4$; ileum, $n=3$ (for immunocytochemistry only) and colon, $n=10$ ) were obtained at surgery from segments of bowel resected for carcinoma or duodenal ulcer. From each specimen, full thickness samples were taken from macroscopically and histologically normal areas at least $8 \mathrm{~cm}$ from the tumour margin. In addition, specimens of antrum, fundus, duodenum, jejunum, ileum and colon were obtained from five rats and nine pigs. All normal tissues were processed for immunocytochemistry and radioimmunoassay.

\section{SURGICAL PROCEDURES}

\section{(a) Extrinsic denervation}

In order to determine whether enteric galaninimmunoreactive nerves have an intrinsic and/or extrinsic origin, portions of rat gut were extrinsically denervated. Six rats (Sprague-Dawley) were anaesthetised with sodium pentabarbitone $(20 \mathrm{mg} / \mathrm{kg}$ ip). The abdomen was opened and the terminal ileum 
exposed. All branches to the ileum arising from the right ileal artery were ligated and cut, thereby removing the perivascular extrinsic nerve supply to the terminal 6-8 $\mathrm{cm}$ of ileum (depending on individual anatomy). After surgery, the animals were allowed to recover and maintain a normal diet for one week, after which they were killed, and a $3 \mathrm{~cm}$ segment was taken from the denervated portion of the terminal ileum. Segments of a similar size were also taken from proximal ileum and from ascending and distal colon, for comparison. The segments were processed for immunocytochemistry and radioimmunoassay.

\section{(b) Gut transection}

To gain information on the direction in which galanin-immunoreactive enteric nerves project, the ileum was transected and sutured together again. Six rats were anaesthetised as above. The abdomen was opened and the ileum exposed. At a point approximately $10 \mathrm{~cm}$ proximal to the ileocaecal valve, the ileum was completely transected but the marginal artery was left intact. The two cut edges were then sutured together. After surgery, the animals were allowed to recover and maintain a normal diet for five days, after which they were killed. Five portions of ileum measuring $1 \mathrm{~cm}$ in length were taken from either side of the cut.

\section{CAPSAICIN TREATMENT}

The possible sensory origin of galanin-containing nerves was investigated by administering the neurotoxic agent capsaicin, known to deplete primary afferent neurones of their neurotransmitter content. ${ }^{5}$ Three neonatal Sprague-Dawley rats received two doses of capsaicin (Fluka) $(50 \mathrm{mg} / \mathrm{kg}$ ) dissolved in vehicle (alcohol: Tween 80: saline, 1:1:8 vol). The first dose was administered subcutaneously on day 2 and the second intraperitoneally on day 3 . Three litter mates received only vehicle. The animals were killed at 2 months of age. In order to test the efficacy of the capsaicin treatment, samples of spinal cord (L4) were removed from the rats. Possible depletion of galanin-containing nerves was investigated in ileal samples, this site having been used frequently in the study of the effects of capsaicin on the gut. ${ }^{6-8}$

TISSUE PROCESSING

Tissue samples were processed for immunocytochemistry and, in certain cases, for radioimmunoassay.

\section{Immunocytochemistry}

The tissues were processed in two ways. Pieces of whole bowel wall, no more than $2 \times 2 \mathrm{~cm}$, were fixed by immersion in $0.4 \%$ benzoquinone in phosphate buffered saline (PBS) (pH 7.1-7.4, 0.01 M phosphate, $0 \cdot 15 \mathrm{M}$ saline) for one to three hours. ${ }^{9}$ After rinsing overnight in PBS containing $15 \%$ sucrose and $0.01 \%$ sodium azide, cryostat blocks were prepared at $10 \mu \mathrm{m}$ sections cut at $-20^{\circ} \mathrm{C}$ and picked up onto glass slides coated with poly-L-lysine. ${ }^{10}$ For whole mount preparations, rings of bowel, at least $3 \mathrm{~cm}$ in length, were opened and fixed by immersion in $0.4 \%$ benzoquinone solution for one to three hours, as before. After washing overnight in rinsing buffer, the tissues were placed, mucosa side down, onto a cork mat, stretched and pinned flat. The longitudinal muscle coat was removed, under a dissecting microscope, with the myenteric plexus attached. The strips of muscle obtained in this way were inverted and placed on a glass slide coated with poly-L-lysine. ${ }^{10}$ The circular muscle coat was then pulled away from the stretched preparation and the submucosa dissected out and placed on a glass slide. In this way, whole mount preparations were made of both of the main ganglionated plexuses.

After being allowed to air dry at room temperature for at least one hour, the sections and whole mount preparations were immunostained. Tissue sections were immunostained with the technique of indirect immunofluorescence ${ }^{11}$ or the peroxidase anti-peroxidase ${ }^{12}$ method, whilst the whole mount preparations underwent only the peroxidase antiperoxidase method. The same procedure for this method was used for both types of specimen.

For indirect immunofluorescence, the primary antiserum to galanin (Gal 8) (Table 1) was applied and left for $16-20$ hours at $4^{\circ} \mathrm{C}$ in a moist atmosphere. To test for the presence of catecholaminergic, and therefore extrinsic, nerves in the specimens from rats with denervated ileum, antibodies to tyrosine hydroxylase, an enzyme active in catecholamine synthesis, were used (Table 1). In addition, to check the effectiveness of the capsaicin treatment, an antiserum to substance $P$ was used (Table 1) on sections of spinal cord and ileum. After three rinses in PBS, the sections were incubated with the second layer of fluorescein-conjugated goat

Table 1 Antisera details

\begin{tabular}{llll}
\hline & \multicolumn{3}{l}{ Dilution } \\
\hline Rabbit antiserum to: & Source & IF & PAP \\
Porcine galanin & HH & $1: 1000$ & $1: 5000$ \\
Rat tyrosine hydroxylase & JT & $1: 400$ & - \\
Synthetic substance P & HH & $1: 500$ & - \\
Porcine VIP & HH & $1: 2000$ & - \\
\hline
\end{tabular}

$\mathrm{HH}=$ Hammersmith Hospital

JT $=\mathrm{J}$ Thibault ${ }^{19}$ 
antirabbit serum (Hoechst UK Ltd.), diluted 1:100 for one hour at room temperature. After repeated washing in PBS, the sections were mounted in PBS-glycerine $(1: 9 \mathrm{v} / \mathrm{v})$ and examined under a Leitz ultraviolet microscope. Photographs were taken using FP4 black and white film (speed 100 ASA) (Ilford Ltd.).

The peroxidase antiperoxidase technique involved the pretreatment of sections and whole mount preparations by immersion in $0.03 \%(\mathrm{v} / \mathrm{v})$ hydrogen peroxide in PBS for 30 minutes to remove endogenous peroxidase activity. Possible background staining was also reduced by the application of normal goat serum, diluted 1:30, for 30 minutes at room temperature. The primary antiserum was applied and incubated for 72 hours at $4^{\circ} \mathrm{C}$ in a moist atmosphere. The second layer of unconjugated goat antirabbit IgG was used at a dilution of 1:200 for 30 minutes. The final layer consisted of rabbit PAP complex, dilution 1:500, and incubation was again for 30 minutes at room temperature. Visualisation of the PAP complex was achieved by the diaminobenzidine method of Graham and Karnovsky. ${ }^{13}$ When developed, the sections were dehydrated, mounted in DPX and examined under a transmitted light microscope (Reichert-Jung). Photographs were taken using Pan F black and white film (speed 50 ASA) (Ilford Ltd.).

Controls for immunostaining included omission of the first layer of antiserum or replacement with non-immune rabbit serum. In addition, immunostaining was successfully quenched by previous absorption of the optimally diluted antiserum with as little as $1.0 \mathrm{nmol}$ of the corresponding antigen $/ \mathrm{ml}$ diluted antiserum.

\section{Coexistence studies}

Comparative immunocytochemistry was used to see if galanin is costored with VIP in the submucous plexus of the pig duodenum, where numerous galanin-immunoreactive ganglion cell bodies can be found. Vasoactive intestinal polypeptide is the only peptide consistently immunostained in a large proportion of these cells. Serial sectioning of nerve fibres is beyond the scope of light microscopical studies, and so the large neuronal cells were sectioned and immunostained for each peptide. Serial sections of $4 \mu \mathrm{m}$ were cut at $-20^{\circ} \mathrm{C}$ from cryostat blocks of porcine duodenum. The first section was picked up directly from the knife onto a glass slide coated with poly-L-lysine. The second section of each pair was gently brushed off the knife onto a chilled surface below, inverted and picked up onto a slide. In this way, the same cut face was uppermost in both sections. ${ }^{14}$ The first section of each pair was immunostained for galanin and the second section with an antiserum against natural porcine VIP (Table 1), using the technique of indirect immunofluorescence as described above.

\section{Tissue extracts}

Samples of normal human, porcine, and rat gut were processed for radioimmunoassay determination of galanin content, as were the extrinsically denervated rat guts and controls.

For extraction, preweighed samples were dropped into polypropylene tubes containing boiling acetic acid $(0.5 \mathrm{~mol} / \mathrm{l}$, approx $10 \mathrm{ml} / \mathrm{g}$ tissue $)$. The tubes were boiled for 20 minutes in a water bath and then cooled at room temperature and were frozen $\left(-20^{\circ} \mathrm{C}\right)$ until required for assay.

\section{Radioimmunoassay}

The radioimmunoassay for galanin is reported in full elsewhere. ${ }^{15}$ Briefly, the purification of the monoiodinated peptide tracer was achieved using high performance liquid chromatography using a Bondapak $\mathrm{C} 18$ column with $30 \%$ acetronitrile and $0 \cdot 1 \%$

Table 2 Summary of immunocytochemical results

\begin{tabular}{|c|c|c|c|c|c|c|c|}
\hline & $L M$ & $M P$ & & $C M$ & $S P$ & $M M$ & $M U C$ \\
\hline \multicolumn{8}{|l|}{ Rat } \\
\hline Fundus & ++ & + & $:-$ & +++ & $+:+$ & + & + \\
\hline Antrum & ++ & + & $:-$ & +++ & $+\quad:+$ & + & + \\
\hline Duodenum & $+t$ & $+t$ & $:+$ & +++ & $++:++$ & + & + \\
\hline Jejunum & ++ & ++ & $:+$ & +++ & $++:++$ & + & + \\
\hline Ileum & ++ & ++ & :t & +++ & $++:+t$ & + & + \\
\hline Colon & ++ & ++ & $:+$ & +++ & $++:++$ & + & + \\
\hline \multicolumn{8}{|l|}{ Pig } \\
\hline Fundus & ++ & + & $:-$ & +++ & $+\quad:+$ & + & + \\
\hline Antrum & ++ & + & $:-$ & ++ & $+\quad:+$ & + & + \\
\hline Duodenum & ++ & ++ & $:-$ & +++ & $++:+t+$ & + & + \\
\hline Jejunum & ++ & ++ & $:-$ & +++ & $++:++$ & + & + \\
\hline Ileum & ++ & ++ & $:-$ & +++ & $++:++$ & + & + \\
\hline Colon & + & ++ & $:-$ & ++ & $++:+t$ & + & + \\
\hline \multicolumn{8}{|l|}{ Human } \\
\hline Fundus & ++ & ++ & $:-$ & +++ & $+\quad:+$ & + & + \\
\hline Antrum & ++ & ++ & $:-$ & +++ & $+\quad:+$ & + & + \\
\hline Small int & ++ & $++t$ & $t:-$ & + & $+:+$ & + & + \\
\hline Large int & ++ & ++ & $:-$ & ++ & $+\quad:+$ & + & + \\
\hline
\end{tabular}

Areas of gut:

LM= longitudinal muscle

$\mathrm{MP}=$ myenteric plexus (fibres: cell bodies)

$\mathrm{CM}=$ circular muscle

$\mathrm{SP}=$ submucous plexus (fibres: cell bodies)

$\mathrm{MM}=$ muscularis mucosae

MUC $=$ mucosa

Results

$-=$ negative

$+=$ few

$++=$ moderate

+++ numerous 
trifluoracetic acid. The specific activity of the label was $60 \mathrm{bequerol} / \mathrm{fmol}(1.6 \mathrm{nCi} / \mathrm{fmol})$. The antibody (designated $\mathrm{Gal}$ 8) was produced in a rabbit immunised with $30 \mathrm{nmol}$ of unconjugated porcine galanin. The final dilution of the antibody was 1:480 000. In a further study, the regional antibody specificity was determined using a C-terminal galanin 10-29 fragment showing that Gal 8 is $\mathrm{N}$ terminally directed. Dose response curves of various mammalian tissue extracts revealed parallel displacement in human and pig but not in rat. The chromatographic identity of galanin could be confirmed in the extracts of all species mentioned. ${ }^{16}$ Statistical analysis of the results for the intact and extrinsically denervated rat guts was made using an unpaired Student's $t$ test.

\section{Results}

NORMAL TISSUES

Immunocytochemistry

Galanin immunoreactivity was localised exclusively to nerves in the gastrointestinal tract of all three mammals investigated. In tissue sections and whole mount preparations, these nerves could be found in each layer of gut wall and at all levels of the tract. The results are summarised in Table 2. In general, few galanin-immunoreactive fibres were detected in the mucosal layer. Most fibres were present in the muscle layers. Galanin-immunoreactive neuronal cell bodies were present only in the submucous plexus of the human and porcine gut. Although they were not present in all areas of the gut, the rat had immunoreactive ganglion cells in both plexuses, with higher numbers being found in the submucous plexus. There were, however, some variations in the distribution in each species.

\section{Rat}

In the stomach, galanin immunoreactive fibres were present mainly in the circular muscle coat. The second most frequent site was the longitudinal muscle and in between, only a fine scattering of immunoreactive fibres could be detected in the

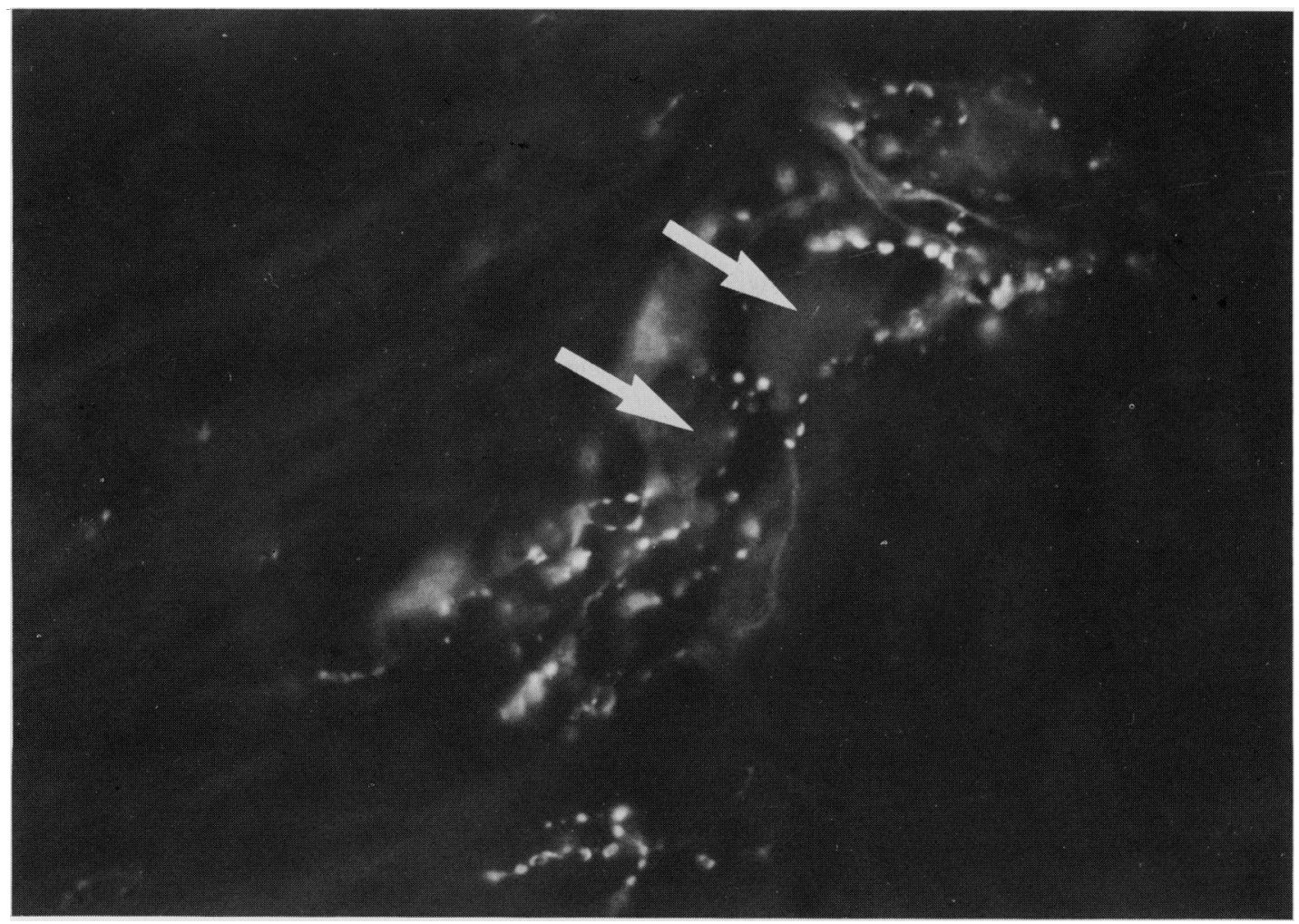

Fig. 1 A fine network of galanin immunoreactive fibres around non-immunoreactive neuronal cell bodies (arrows) in the myenteric plexus of rat stomach, demonstrated by the technique of indirect immunofluorescence. 
myenteric plexus. No neuronal cell bodies were found to contain galanin in the myenteric plexus (Fig. 1). In the submucosa, the fibres were again few and scattered, sometimes laying near ganglion cells, a few of which were immunoreactive. A small number of single fibres could be seen in the muscularis mucosae but galanin-immunoreactive fibres were rare in the mucosa. This pattern changed in the duodenum, which received a heavier supply of galanin-immunoreactive nerves. Fibres were more prominent in the mucosa, although the total numbers were still quite low, and they lay mainly toward the base of the mucosal layer. The submucous plexus was more densely innervated than in the antrum and immunoreactive ganglion cells were seen more frequently. These numbered up to half of the cells in each group. The galanin innervation of the muscle layers was similar to that seen in the antrum and fundus but in the myenteric plexus a thicker mesh of fibres could be discerned. Some immunoreactive ganglion cells were found in this plexus. In the other areas of gut, a similar distribution of galanin-immunoreactive nerve fibres was seen as in the duodenum, with immunoreactive cell bodies being found in the myenteric and submucous plexuses.

\section{Pig}

As in the rat, galanin-immunoreactive fibres were found only rarely in the mucosa of the porcine stomach. The general distribution of the fibres in this area was similar to that in the rat except that fewer fibres could be found in the circular muscle of the antrum in comparison with that of the fundus.

The duodenal submucous plexus was richly supplied with immunoreactive neuronal cell bodies and fibres. The cell bodies often formed more than half the total neurones in a group. The mucosa also received a greater supply of galanin nerves than was seen in any other area of pig, rat or human gut. The

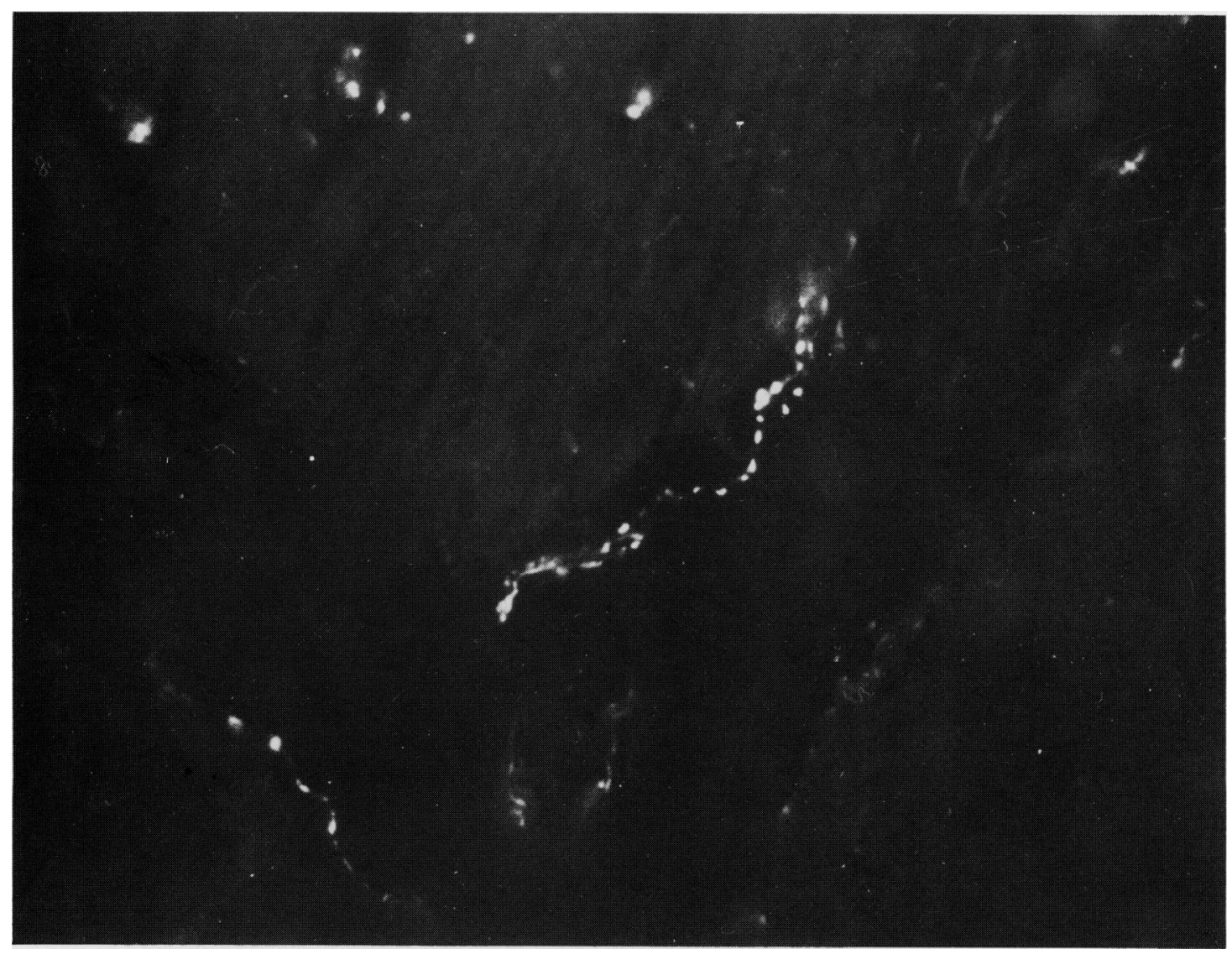

Fig. 2 Galanin containing fibres lying along the edge of the circular muscle coat and in the submucosa of porcine duodenum. 
myenteric plexus and muscle coats (Fig. 2) of the porcine duodenum were innervated to a similar extent as the rat duodenum, except that no immunoreactive ganglion cells were found.

The jejunum and ileum contained a similar pattern of galanin-immunoreactive fibres to that seen in the rat but with no immunoreactive ganglion cells being found in either plexus. There was a distinct reduction in fibres in the muscle layers in the colon as compared with the small bowel, but the other layers showed no change.

\section{Human}

Galanin-immunoreactive nerves were scattered throughout the human stomach and were equally numerous in the antrum and fundus. Immunoreactive ganglion cells were not very frequent in the submucous plexus.

In the human small bowel, galanin immunoreactive fibres were comparatively infrequent. They were scattered in the mucosal layer, muscularis mucosae and submucosa. Few immunoreactive cell bodies were detected (Fig. 3). More fibres were found in the longitudinal than the circular muscle but most fibres were found in the myenteric plexus, where they showed a distinct localisation around the edge of the plexus, away from the neuronal cell bodies.

The large bowel also showed less galanin-immunoreactive nerves than those of rat or pig bowel, but more fibres were found at this site than in the small bowel. The overall distribution was similar in the wall but fibres were more frequent in the submucosal and mucosal layers.

\section{Radioimmunoassay}

Concentrations of galanin immunoreactivity in the gastrointestinal tracts of the three species studied are shown in Table 3. Galanin immunoreactivity was present throughout the intestine. Concentrations were generally greater in the porcine gut than in the other two species. Also, the pattern of distribution in the pig appeared to be different from the other two species, with concentrations increasing caudally.

\section{Effect of extrinsic denervation}

Immunocytochemistry detected similar populations of galanin immunoreactive nerve fibres and ganglion cells in the specimens taken from operated rats and

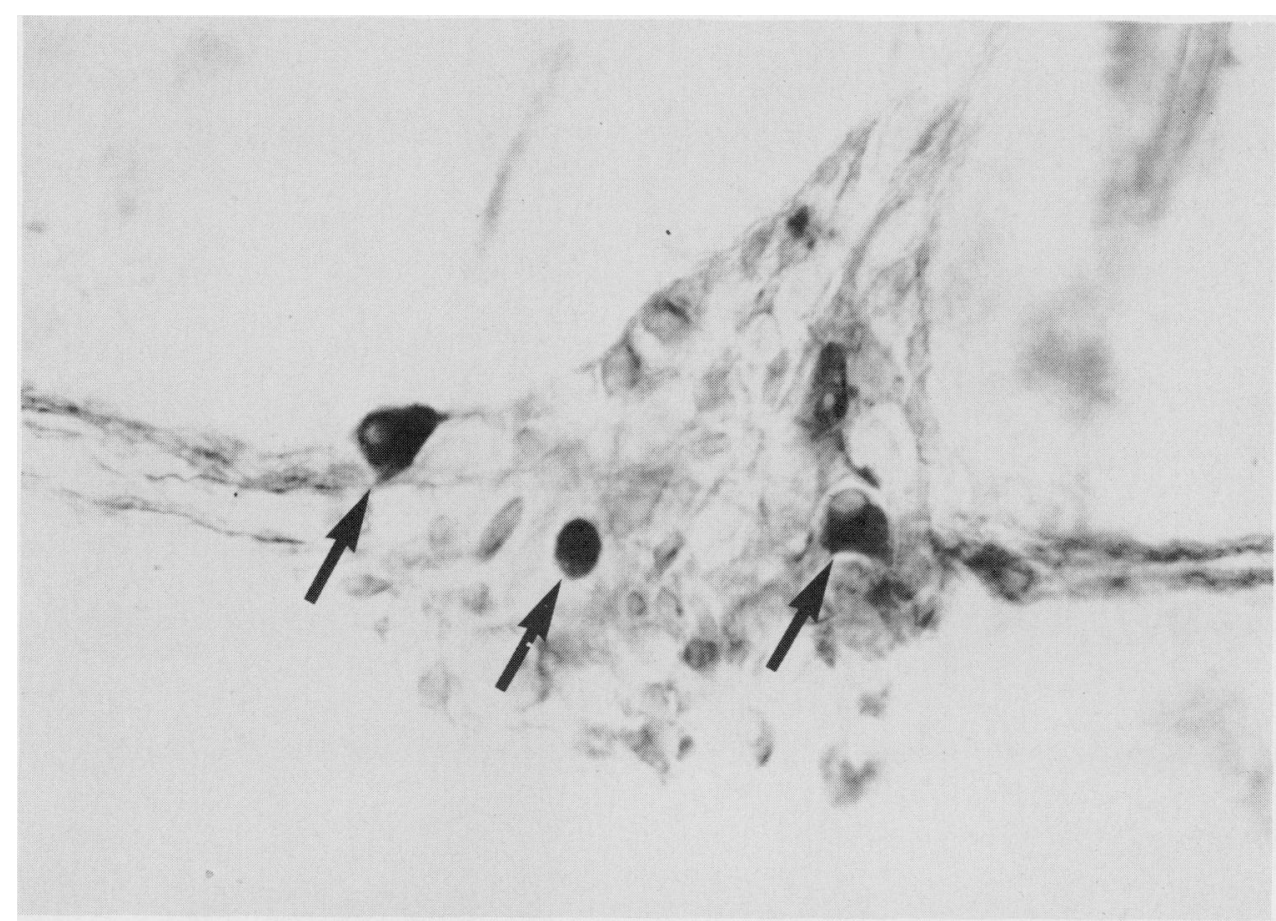

Fig. 3 A whole mount preparation of the submucous plexus of human ileum immunostained for galanin using the peroxidase antiperoxidase method. Galanin immunoreactive fibres can be seen intermingled with neuronal cell bodies, three of which are immunoreactive (arrows). 
Table 3 Concentrations of galanin in mammalian gut

\begin{tabular}{|c|c|c|c|}
\hline & \multicolumn{3}{|c|}{ Galanin pmol/g (mean $\pm S E M)$} \\
\hline & Rat & Human & Pig \\
\hline Fundus & $5 \cdot 4 \pm 1 \cdot 1$ & $9 \cdot 3 \pm 1 \cdot 6$ & $6 \cdot 7 \pm 1 \cdot 1$ \\
\hline Antrum & $3 \cdot 7 \pm 0 \cdot 7$ & $8 \cdot 6 \pm 1 \cdot 7$ & $11 \cdot 5 \pm 3 \cdot 9$ \\
\hline Duodenum & $8 \cdot 6 \pm 1 \cdot 5$ & $12 \cdot 1 \pm 1 \cdot 6$ & $30 \cdot 3 \pm 5 \cdot 8$ \\
\hline Jejunum & $5 \cdot 5 \pm 1 \cdot 2$ & $6 \cdot 2 \pm 1 \cdot 5$ & $18 \cdot 2 \pm 3 \cdot 4$ \\
\hline Ileum & $10 \cdot 4 \pm 1 \cdot 5$ & $*$ & $41 \cdot 2 \pm 8 \cdot 7$ \\
\hline Colon & $5 \cdot 1 \pm 0 \cdot 9$ & $3 \cdot 3 \pm 0 \cdot 3$ & $76 \cdot 5 \pm 14 \cdot 3$ \\
\hline
\end{tabular}

$*=$ not done

the control animals. The operated areas of gut were shown to have undergone successful extrinsic denervation by their total lack of tyrosine hydroxylaseimmunoreactive nerves. The concentrations of galanin in denervated and normal areas of gut as measured by radioimmunoassay are displayed in Table 4. No significant change occurred in the content of galanin after extrinsic denervation $(\mathrm{p}<0 \cdot 05)$.

\section{Effect of gut transection}

Immunostaining of galanin in the $1 \mathrm{~cm}$ segments of rat ileum taken from either side of the transection showed a complete loss of fibres from the $1 \mathrm{~cm}$ distal to the cut. Some fibres were found in the second portion taken distally, mainly in the myenteric plexus and circular muscle. This suggests that the galanin-immunoreactive fibres project mainly in a caudal direction. The other distal portions, removed 3,4 , and $5 \mathrm{~cm}$ distal to the cut, had apparently normal galanin innervation. Thus, the fibres apparently project for $1-2 \mathrm{~cm}$.

The segments of bowel taken $2,3,4$, and $5 \mathrm{~cm}$ proximal to the transection had normal galanin innervation. Some changes in galanin-immunoreactive nerves could be observed in the $1 \mathrm{~cm}$ portion immediately proximal to the lesion. Many fibres, particularly at the distal margin of the $1 \mathrm{~cm}$ length, were thicker than normal and densely

Table 4 Concentrations of galanin in control and denervated rat intestine

\begin{tabular}{lcr}
\hline & \multicolumn{2}{c}{ Galanin pmol/g $($ mean \pm SEM) } \\
\cline { 2 - 3 } & Controls & Operated \\
\hline Proximal ileum & $9 \cdot 6 \pm 1 \cdot 0$ & $7 \cdot 9 \pm 0 \cdot 8$ \\
$\begin{array}{l}\text { Terminal ileum (extrinsically } \\
\text { denervated) }\end{array}$ & $10 \cdot 9 \pm 1 \cdot 7$ & $7 \cdot 9 \pm 1 \cdot 7$ \\
Ascending colon & $9 \cdot 8 \pm 0 \cdot 9$ & $12 \cdot 2 \pm 2.5$ \\
Distal colon & $8 \cdot 7 \pm 0 \cdot 5$ & $6 \cdot 5 \pm 0 \cdot 8$ \\
\hline
\end{tabular}

immunostained. In addition, immunoreactive ganglion cells were more frequent in the submucous plexus and an occasional one could also be found scattered in the myenteric plexus. The fibres emanating from the immunoreactive cells at the distal margin were clearly abnormal, having a thick, stumpy appearance. These results were very similar to those obtained for VIP-immunoreactive nerves, which have been shown previously to project in a caudal direction. ${ }^{17}$

\section{Capsaicin treatment}

The effectiveness of capsaicin treatment of rats was assessed by immunostaining of substance $P$ in the spinal cord. A marked reduction of immunoreactivity was noticeable in the nerve terminals of the dorsal horn. In the gut, a loss of small proportion of the substance P-containing nerves of the gut was noted in comparison with the vehicle treated controls. The changes were particularly evident in nerve fibres near blood vessels and, to a lesser extent, in immunoreactive fibres of the myenteric plexus. These observations are in agreement with the previous report that the sensory component of ileal substance $\mathrm{P}$ nerves is comparatively minor.

In contrast, with the substance $P$ nerves, no obvious loss of galanin-immunoreactive fibres or cell bodies could be detected in the ileal segments of treated animals.

\section{Coexistence}

In all species examined, it was possible to find galanin and VIP immunoreactivity in the same ganglion cells of the submucous plexus (Fig. 4). Sometimes - for example, in pig duodenum, all VIPimmunoreactive neuronal cell bodies of the submucosa appeared to contain galanin. In most regions, however, subjective assessment showed that up to two thirds of the VIP-immunoreactive cells displayed this colocalisation. Only a few ganglion cells were found to contain galanin alone.

\section{Discussion}

Galanin immunoreactivity was found throughout the gastrointestinal tracts of man, pig, and rat, and was shown by immunocytochemistry to be present exclusively in neuronal structures, which were found in all layers of the gut wall, except the epithelium. The quantities of extracted galanin measured by radioimmunoassay varied greatly but were generally higher in the large bowel, reaching a maximum value of $76.5 \pm 14 \mathrm{pmol} / \mathrm{g}$ in porcine colon. The concentrations of galanin in the rat gut were slightly lower than those previously reported. ${ }^{2}$ Galanin thus joins the large group of peptides, including VIP, 

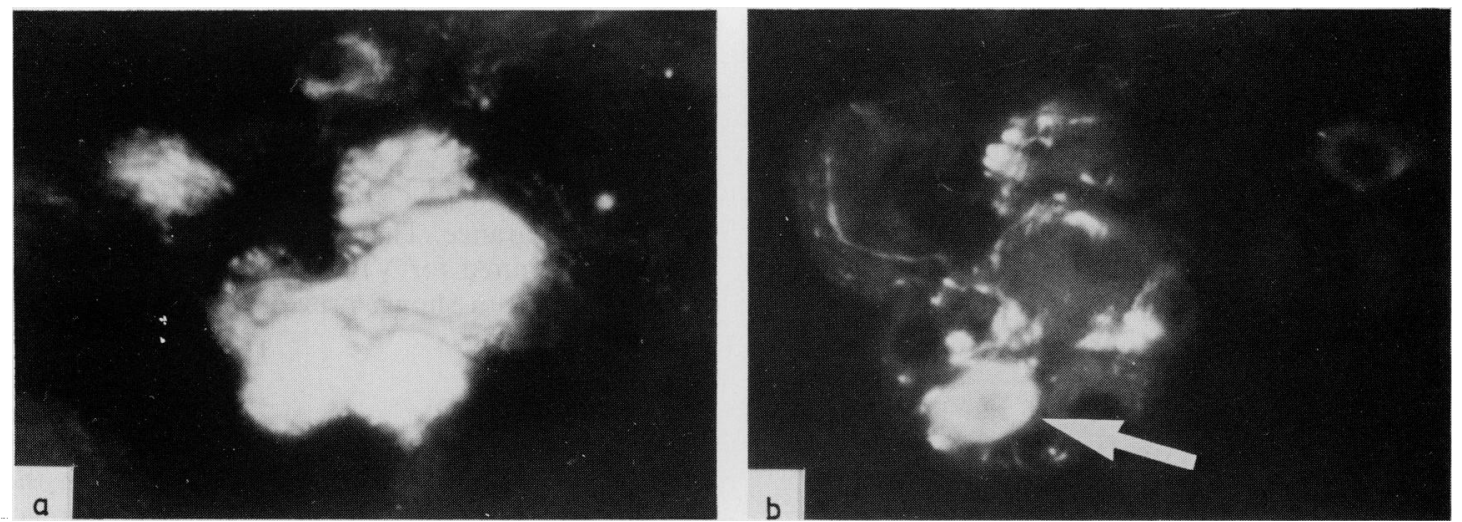

Fig. 4 Serial 4 um cryostat sections of the submucosa of porcine duodenum immunostained for: (a) VIP (b) Galanin. All of the ganglion cells contain VIP immunoreactivity and one shows galanin immunoreactivity in the serial section (arrow).

substance $P$ and the enkephalins, which functions within the mamalian enteric nervous system and contributes to the control of gut physiology.

The finding of galanin-immunoreactive ganglion cell bodies in the submucous plexus suggested that these nerves may have a wholly or partly intrinsic origin. This possibility was investigated by extrinsically denervating a series of animals. No significant loss of galanin could be detected, either morphologically or biochemically, indicating that, in the rat at least, the nerves arise predominantly from the submucous plexus and are, thus, part of the intrinsic nervous system of the gut. The possibility cannot be ruled out, however, that there is a minor component of the enteric galanin innervation which arises from an extrinsic source. The finding of galanin in primary afferent neurones ${ }^{15}$ suggests that the peptide may be involved in sensory neurotransmission. Neonatal application of the neurotoxin capsaicin has been shown to cause degeneration of small diameter primary afferent fibres. ${ }^{5}$ In this study, capsaicin did not appear to cause any reduction in enteric galanincontaining nerves. The efficacy of capsaicin in depleting substance $P$ was assessed not only in the gastrointestinal tract, but also in the spinal cord where nerve terminals of the dorsal horn were markedly depleted of substance P immunoreactivity in the same animals. Although the persistence of galanin-containing enteric nerves after capsaicin treatment argues against galanin having a sensory role in the gut, it is possible that any galanincontaining sensory tibres may be too tew, in comparison with the total population, to make a noticeable difference when depleted. A somewhat similar situation has been shown for substance $P$ containing nerves, where the extrinsic sensory com- ponent forms only a small proportion of the total nervous population. ${ }^{7}$

Galanin nerves appear to project predominantly in a caudal direction. This was shown not only by the loss of galanin-immunoreactive nerves from ileum distal to a transection but also by the formation of abnormal fibres in the proximal region. The morphological abnormalities observed were probably due to the axonal damage incurred by the transection. The general distribution pattern of galaninimmunoreactive nerves was in many ways similar to those containing VIP, one of the most abundant peptides in the enteric nervous system. Both peptides occur solely in nerves, which are present at all levels of the tract and in each layer of the gut wall; and the two types of nerve appear to project mainly in a caudal direction. Galanin and VIP are also both present in ganglion cells of the submucous plexus. There appear to be two main differences in the distributions of the peptides. Firstly, galanin-immunoreactive fibres are infrequent in the mucosal layer compared with VIP nerves, which form a dense plexus at this site. Secondly, galanin nerves show no particular association with the vascular system of the gut. The finding of both galanin and VIP in a population of submucosal ganglion cells, however, underlines the possible overlap in their distributions. Coexistence of peptides within the same cells of the enteric nervous system has been demonstrated previously. ${ }^{14} 18$ The finding of both VIP and galanin in a population of neuronal cell bodies gives rise to speculation on possible functional relationships. Little is known at the moment, however, about the gastrointestinal actions of galanin, apart from its ability to contract isolated preparations of rat enteric smooth muscle. ${ }^{1}$ 
The demonstrated localisation of galanin, its presence in significant concentrations in the gastrointestinal tract and its reported contractile activity $^{1}$ suggest that this newly discovered gut neuropeptide may have a role in physiological regulation of muscle tone and gut motility.

Pure natural galanin was kindly supplied by $\mathrm{Dr} \mathrm{K}$ Tatemoto, Department of Biochemistry II, Karolinska Institute, Stockholm, Sweden, and the antibodies to tyrosine hydroxylase by $\mathrm{Dr} \mathrm{J}$ Thibault, College de France, Biochimie Cellulaire, Paris, France.

\section{References}

1 Tatemoto K, Rokacus A, Jornvall H, McDonald TJ, Mutt V. Galanin - a novel biologically active peptide from porcine intestine. FEBS Lett 1983; 164: 124-8.

2 Rokaeus A, Melander T, Hökfelt T, et al. A galaninlike peptide in the central nervous system and intestine of rat. Neurosci Lett 1984; 47: 161-6.

3 Melander T, Hokfelt T, Rokacus A, Fahrenkrug J, Tatemoto K, Mutt V. Distribution of galanin-like immunoreactivity in the gastro-intestinal tract of several mammalian species. Cell Tiss Res 1985; 239: 253-70.

4 McDonald TJ, Dupre J, Tatemoto K, Greenberg GR, Radzuik J, Mutt V. Galanin inhibits insulin secretion and induces hyperglycaemia in dogs. Diabetes $1985 ; 34$ : 192-6.

5 Fitzgerald $M$. Capsaicin and sensory neurons - a review. Pain 1983; 15: 109-30.

6 Bartho L, Szolcsanyi J. The site of action of capsaicin on the guinea pig isolated ileum. NaunynSchmiedeberg's Arch Pharmacol 1978; 305: 75-81.

7 Furness JB, Papka RE, Della NG, Costa M, Eskay RL. Substance P-like immunoreactivity in nerves associated with the vascular system of guinea pigs. Neuroscience 1982; 7: 447-59.

8 Chahl LA. Evidence that the contractile response of the guinea pig ileum to capsaicin is due to substance $\mathrm{P}$ release. Naunyn-Schmiedeberg's Arch Pharmacol 1982; 319: $212-5$.
9 Bishop AE, Polak JM, Bloom SR, Pearse AGE. A new universal technique for the immunocytochemical localisation of peptidergic innervation. J Endocrinol 1978; 77: $25-6$.

10 Huang WM, Gibson SJ, Facer P, Gu J, Polak JM. Improved section adhesion for immunocytochemistry using high molecular weight polymers of L-lysine as a slide coating. Histochemistry 1983; 77: 275-9.

11 Coons AH, Leduc HH, Connolly JM. Studies on antibody production. $J$ Exp Med 1955; 102: 49-60.

12 Sternberger LA. The unlabelled antibody peroxidase anti-peroxidase (PAP) method. In: Sternberger LA, ed. Immunocytochemistry. New York: John Wiley, 1979: 104-69.

13 Graham RC, Karnovsky MJ. The early stages of absorption of injected horse-radish peroxidase in the proximal tubules of mouse kidney. $J$ Histochem Cytochem 1976; 14: 291-302.

14 Bishop AE, Polak JM, Yiangou Y, Christofides ND, Bloom SR. The distributions of PHI and VIP in porcine gut and their co-localisation to a proportion of intrinsic ganglion cells. Peptides 1984; 5: 255-9.

15 Ch'ng JLC, Christofides ND, Anand P, et al. Distribution of galanin immunoreactivity in the central nervous system and the responses of galanin-containing neuronal pathways to injury. Neuroscience 1985; 16: 343-54.

16 Bauer FE, Adrian TE, Christofides ND, et al. Molecular heterogeneity of galanin in human, pig, guinea pig and rat intestine. Gastroenterology (In press).

17 Furness JB, Costa M. Types of nerves in the enteric nervous system. Neuroscience 1980; 5: 1-20.

18 Schultzberg M, Hökfelt T, Nilsson G, et al. Distribution of peptide- and catecholamine-containing neurons in the gastrointestinal tract of rat and guinea pig: immunohistochemical studies with antisera to substance $P$, vasoactive intestinal polypeptide, enkephalins, somatostatin, gastrin/cholecystokinin, neurotensin, and dopamine- $\beta$-hydroxylase. Neuroscience 1980 ; 5: 689744.

19 Thibault J, Vidal D, Gros F. In vitro translation of mRNA from rat phaeochromocytoma tumours, for characterisation of tyrosine hydroxylase. Biochem Biophys Res Commun 1981; 99: 960-8. 